\title{
Investigation of Pectin-Hydroxypropyl Methylcellulose-Coated Floating Beads for Pulsatile Release of Piroxicam
}

Dipali Kamble, Dilesh Singhavi, Shrikant Tapadia, Shagufta Khan Institute of Pharmaceutical Education and Research, Borgaon (Meghe), Wardha442001, Maharashtra, India

\section{ABSTRACT}

Objectives: The present study was aimed at preparing pectin-hydroxypropyl methylcellulose-coated floating beads for pulsatile release of piroxicam in the treatment of early morning inflammation.

Materials and Methods: Piroxicam-loaded beads were prepared from sodium alginate and hydroxypropyl methylcellulose (HPMC) in different concentrations of calcium carbonate using the ionotropic gelation method. In order to avoid the drug release in the upper part of the gastrointestinal tract, the beads were coated with a pectin-HPMC layer using the dip coating method. Size analysis and encapsulation efficiency, drug loading, in vitro release, swelling behaviour and surface morphology studies of the beads were carried out.

Results: The In vitro release study revealed that the pectin-HPMC coating of the beads prevented the release of the drug in an acidic medium and provided pulsed release of the drug after a lag time. Formulation CF4 (containing calcium carbonate in the ratio 3:4 with respect to sodium alginate) exhibited a pulsed release of $95.55 \%$ at the end of 7 hours in phosphate buffer, which was after the desired lag time of 6 hours.

Discussion and Conclusion: The study revealed that optimized floating pulsatile beads coated with pectin-HPMC can efficiently retain the piroxicam in an acidic medium and that there is a pulsed release in an alkaline medium after a lag time. It also showed that prepared beads can potentially be used for chronotherapeutic treatment of the disease associated with early morning inflammation.

Key words: Beads, Floating, Hydroxypropyl methylcellulose, Pectin, Pulsatile

Running Title: Floating Rulsatile Beads for Piroxicam

\section{INTRODUCTION}

Drug delivery systems based on circadian variations is gaining much attention. ${ }^{1}$ Several diseases treated by chronotherapeutics, such as asthma, hypertension, arthritis and peptic ulcers, require an instantaneous and complete release of a drug after a scheduled time for effective action. Pulsatile drug delivery systems are developed to deliver drugs at the right time, in the right amount and the right site of action and thus improve the patient compliance. ${ }^{2}$ Time-controlled and site-specific drug delivery systems must be programmed such that they can be administered at bedtime and the drugs are released rapidly when the symptoms worsen. Pulsatile drug delivery systems have short residence times in the stomach though they release drugs after certain lag times. Different approaches have been developed to improve the retention time and bioavailability of drugs in the gastrointestinal tract (GIT), such as intragastric floating formulations, magnetic formulations, extensible or swellable formulations and super porous hydrogel gel formulations. ${ }^{3}$ Multiple-unit dosage forms have various advantages over monolithic-type dosage forms in reducing the 
intersubject and intrasubject variabilities of the transit due to the all-or-nothing emptying process. Various approaches have been used to impart buoyancy to multiple-unit dosage forms. These involve effervescent systems or non-effervescent systems. ${ }^{4}, 5$ Jagdale SC et al. developed press-coated floating pulsatile tablets of lisinopril for the treatment of hypertension. ${ }^{6}$ Gadad AT et al. formulated hollow multiparticulate floating formulations using low-methoxy pectin and gellan gum as polymers for site- and time-specific delivery of antihypertensive drugs. ${ }^{7}$

The aim of the present investigation was to design and evaluate floating pulsatile beads of piroxicam (PX). Low-methoxy pectin (LM PC) can be used as a coating material to avoid the drug release in the acidic medium. LM PC has a strong coating film-forming property, but it is highly soluble in water. Due to this water solubility, it cannot be used to prevent the release of PX to greater extent in upper GIT. Absorption of water may lead to weakening of the rigid gel structure of an LM PC coating. The use of hydroxylpropyl methylcellulose (HPMC) E50 LV along with LM PC not only maintains the gel structure but also gives strength and better coating properties. ${ }^{8}, 9$ PX was incorporated in sodium alginate (SA) and HPMC E50 LV polymeric membrane along with a gas-forming agent (calcium carbonate) so that the beads would remain buoyant in the stomach for a longer duration. The addition of LM PC to HPMC E50 LV coating layer to reduce the release of PX from floating pulsatile beads in an acidic medium is being reported for the first time in the present work. The prepared beads were coated with LM PC-HPMC E50 LV to prevent the drug release in the upper portion of the GIT. The prepared beads were subjected to size analysis, a swelling study and an erosion study and evaluated for drug content, encapsulation efficiency, floating properties and in vitro drug release. Fourier transform infrared spectroscopy study was carried out, and the surface morphology was studied.

\section{MATERIALS AND METHODS}

Materials

PX was obtained as a gift sample from Apex Health Care Ltd (Gujarat). SA, HPMC K15M, LM PC, HPMC E50 LV and calcium chloride were obtained from LOBA Chemical Pvt Ltd (Mumbai). All other chemicals were of analytical grade.

Selection of polymer combinations

Nine formulations were made using the ionotropic gelation method with SA and different polymers (xanthum gum, HPMC K100 M and HPMC K15 M) in different ratios keeping total polymer weight constant. The concentrations of the drug, crosslinking agent $(2 \% \mathrm{w} / \mathrm{v}$ calcium chloride solution in $1 \% \mathrm{v} / \mathrm{v}$ acetic acid aqueous solution) and floating agent were maintained constant, as shown in Table 1. The beads were observed, and a promising polymer ratio was selected visually.

Effect of concentration of calcium chloride on formation of beads

The polymers selected from a previous study, HPMC K15 M and SA, were weighed accurately in the ratio 9.3:0.7. The HPMC K15 M was soaked overnight in deionized water, and the SA was dissolved in it. A syringe with a $23 \mathrm{G}$ needle was used to extrude the resultant solution into $50 \mathrm{ml}$ of a crosslinking solution containing different concentrations of calcium chloride $(2 \%, 3 \%$ and $4 \% \mathrm{w} / \mathrm{v})$. The effect of concentration of calcium chloride on the formation of beads was observed visually. The polymer combination of SA:HPMC k15 M in the ratio 9.3:0.7 and a $3 \%$ calcium chloride crosslinking solution were selected for further studies.

Preparation of PX-loaded floating pulsatile beads ${ }^{10}$ 
PX-loaded beads were prepared using the ionotropic gelation method. An aqueous polymeric solution $(10 \% \mathrm{w} / \mathrm{v})$ of SA and HPMC K15 M (in the ratio 9.3:0.7) was prepared using deionized water. PX was dispersed uniformly using a magnetic stirrer running at a speed of $150 \mathrm{rpm}$. Calcium carbonate at different concentrations was added to this mixture as shown in Table 2, and the resulting dispersion was sonicated for 15 minutes in a sonicator to remove any air bubbles that formed during the mixing process. The prepared dispersion was extruded using a $23 \mathrm{G}$ needle and syringe into a crosslinking solution $(3 \% \mathrm{w} / \mathrm{v}$ calcium chloride solution in deionized water containing $1 \% \mathrm{v} / \mathrm{v}$ acetic acid). The loosely formed beads were cured by stirring using a magnetic stirrer running at $150 \pm 5 \mathrm{rpm}$ for 15 minutes. The prepared beads were seperated by filtration, washed three times with deionized water and subsequently dried at room temperature.

\section{Coating of floating pulsatile beads}

Film-forming study ${ }^{10,11}$

The solvent casting method was used to prepare films. LM PC $(2 \% \mathrm{w} / \mathrm{v})$ and HPMC E50 LV $(0.1 \% \mathrm{w} / \mathrm{v})$ were dissolved in deionized water and allowed to stand and swell. A plasticizer (polyethelene glycol $600,0.1 \% \mathrm{v} / \mathrm{v}$ ) was added dropwise so that a homogenous solution was achieved. The solution was kept undisturbed for some time to allow air bubbles to escape. The solution was poured into Petri dish. The Petri dish was maintained at $40^{\circ} \mathrm{C}$ for 24 hours to carry out evaporation in a controlled manner. The film-forming ability, physical appearance and texture of the coating solution were evaluated visually.

Procedure for coating beads

PX-loaded uncoated beads were dip-coated uniformly in coating solution containing LM PC $(2 \% \mathrm{w} / \mathrm{v})$ and HPMC E50 LV $(0.1 \% \mathrm{w} / \mathrm{v})$ for 3 minutes. The coated beads were dried at room temperature and kept in an airtight container for further use.

Encapsulation efficiency (EE) and drug-loading efficiency ${ }^{12-14}$

Accurately weighed PX-loaded beads $(50 \mathrm{~g})$ from each batch were crushed by mortar and pestle. The crushed beads were added to $50 \mathrm{ml}$ of phosphate buffer (pH 7.4). The resulting solution was stirred using a magnetic stirrer for 24 hours and filtered through Whatman filter paper 42. The filtered solution was diluted sufficiently, and the absorbance was read at $353.80 \mathrm{~nm}$ with phosphate buffer $(\mathrm{pH} \mathrm{7.4)}$ as the blank solution. The percentage encapsulation efficiency and drug-loading efficiency were determined using the following equations:

$\%$ encapsulation efficiency $=\frac{\text { Actual drug content }}{\text { Theoretical drug content }} \times 100$

$\%$ drug-loading efficiency $=\frac{\text { Weight of drug in beads }}{\text { Weight of drug-loaded beads }} \times 100$

Floating property study $12,13,15$

Floating properties of the beads, such as the total floating time and floating lag time, were determined by placing them $(n=50)$ in a USP Type II Dissolution Apparatus (Model No. DA-3, Veego Scientific Devices, Mumbai, India) filled with $500 \mathrm{ml}$ of $\mathrm{pH}$ 1.2 buffer. The paddle speed was kept at $100 \mathrm{rpm}$, and the temperature was maintained at $37 \pm 0.5^{\circ} \mathrm{C}$. The buoyancy of the beads was observed by visual inspection.

Particle size analysis ${ }^{12-14}$ 
An imaging system (Biowizard Software 4.1) was used to the determine particle size of the beads. The diameters of 20 beads were determined.

In-vitro drug release ${ }^{13-15}$

The release profiles of the PX from the different formulations were obtained using a USP Type I Dissolution Apparatus operated at $100 \mathrm{rpm}$. Prepared beads equivalent to $20 \mathrm{mg}$ PX were kept in a basket that was inserted in $500 \mathrm{ml}$ of the dissolution medium at $37 \pm 0.5^{\circ} \mathrm{C}$. A release study was carried out with a $\mathrm{pH} 1.2$ buffer for the first 2 hours and then with a phosphate buffer $(\mathrm{pH} \mathrm{7.4)}$ for 10 hours. Samples were withdrawn at predetermined time periods and passed through Whatman filter paper. The samples were then diluted sufficiently and analysed spectrophotometrically at $335 \mathrm{~nm}$ and $353.8 \mathrm{~nm}$ in a pH 1.2 and $\mathrm{pH} 7.4$ buffer, respectively. The amount of drug release was determined from the standard calibration curve of $P X$ in both the media. Callibration curve in both the media obeyed Beer-Lambert's law within concentration range of $0-20(\mu \mathrm{g} / \mathrm{ml})$ with correlation coefficient (R2) of 0.999.

Swelling study ${ }^{16}$

Accurately weighed beads $(40 \mathrm{mg})$ were placed in the basket of a USP Type I Dissolution Apparatus containing $500 \mathrm{ml}$ of a buffer solution. Considering the floating characteristics of the beads, the swelling study was carried out in a $\mathrm{pH} 1.2$ buffer solution and then in a $\mathrm{pH} 7.4$ phosphate buffer maintained at $37 \pm 0.5^{\circ} \mathrm{C}$, with the basket being rotated at $100 \mathrm{rpm}$. The baskets were withdrawn at pre-determined intervals, blotted to remove excess water and immediately weighed. The swelling index of the beads was calculated as the relative weight gain/loss of the beads according to the following equation:

$\%$ swelling index $=\frac{W s-W d}{W d} \times 100$

where

$W s=$ weight of swollen beads

$W d=$ weight of dried beads

The change in swelling with time was noted.

\section{Scanning electron microscopy ${ }^{17}$}

The external morphology of the prepared beads (size, shape and surface) was studied using scanning electron microscopy. The beads of the optimized batch (CF4) were kept on double-sided copper conductive tape (NEM Nisshin EM Co Ltd) fixed on aluminium stubs. The beads were then coated with a thin layer of gold sputtering in vacuum for 45 seconds at $\mathrm{I}=20 \mathrm{~mA}$ using a coating unit (Cressington 108 auto sputter coater, UK) to be made electrically conductive. They were then analysed using a scanning electron microscope (Supra 5 Carl Zeiss, Germany) operated at \% $\mathrm{kV}$.

Stability study ${ }^{18,19}$

Stability study was performed by maintaining the optimized formulation at $40 \pm 0.5^{\circ} \mathrm{C}$ and $75 \pm 5 \% \mathrm{RH}$ for 90 days. The samples were tested for the drug content after 0 , 30,60 and 90 days. The formulation was analysed for drug loading efficiency and floating ability. The physical appearance of the formulation was noted, and an in vitro release study was carried out.

Data analysis ${ }^{20}$

All the data were represented as the mean \pm standard deviation. The drug entrapment efficiency, floating duration and mean particle size were compared using 
one-way analysis of variance (ANOVA), and the difference between the means for significance was observed using Tukey's HSD post-hoc test (GraphPad Prism InStat software).

\section{RESULTS AND DISCUSSION}

Crosslinking of the alginate with the divalent calcium ion is responsible for the formation of beads. ${ }^{21}$ Carbon dioxide is liberated as gas bubbles in the chemical reaction between calcium carbonate and acetic acid. This was responsible for the floating of the beads.

The percent encapsulation efficiency of the PX-loaded uncoated formulations was found to be in the range from $98.56 \pm 0.12 \%$ to $90.12 \pm 0.23 \% \mathrm{w} / \mathrm{w}$ (Table 2). The percent drug loading of the uncoated formulations F1-F5 was found to be in the range from $28.15 \pm 0.15 \%$ to $15.30 \pm 0.13 \% \mathrm{w} / \mathrm{w}$. The percent drug loading of the coated formulations CF1-CF5 was found to be in the range from $28.15 \pm 0.15$ to $14.20 \pm 0.13$. A reduction in percent encapsulation efficiency and percent drug loading was observed due to an increase in the proportion of the gas-forming agent. The increased formation of gas led to a reduction in extent of the rigid structure of the beads due to increased pore density and diameter. This results in the leaching of the drug during the formation of the beads, which led to reduced entrapment of drug molecules. ${ }^{[1,12-15]}$ No significant difference was observed $(P>0.05)$ in the drug loading efficiency between the coated and uncoated formulations.

Carbon dioxide gas was generated due to the reaction between the gas-forming agent, i.e. calcium carbonate, and the acidic medium. The generated gas was entrapped in a polymeric network of SA and HPMC K15M and imparted buoyancy to the beads. The floating properties of the uncoated beads and coated beads are shown in Tables 2 and 3 . As the amount of gas-forming agent present in the formulation during the formation of beads was increased, the floating duration increased. The increased porosity of the beads might due to the generation of greater amounts of gases, which led to a reduction in the density of beads, resulting in the improved floating duration. The reduced proportion of the high-density SA in the beads also led to the formation of lighter beads. The paddle speed does not affect the floating properties of the beads. The beads were able to float until disintegration occurred. Thus, in both the coated and uncoated formulations, as the concentration of the gas-forming agent was increased, the porosity was increased, causing them to remain buoyant for a longer duration. ${ }^{12-15,22}$ The differences between the floating duration of the coated and uncoated formulations were insignificant $(P>0.05)$.

The mean particle size of the formulations F1-F5 was found to be in the range from $1.348 \pm 0.012 \mathrm{~mm}$ to $1.576 \pm 0.011 \mathrm{~mm}$, while that of the coated formulations was found to be in the range from $1.431 \pm 0.014 \mathrm{~mm}$ to $1.661 \pm 0.061 \mathrm{~mm}$. From the results (Table 2), it may be seen that increasing the amount of gas-forming agent led to an increase in the bead diameter due to increases in the number and size of pores. Again, the formation of more gas results in a less dense bead structure of greater size. The beads of batch $\mathrm{F} 5$, with a higher concentration of gas-forming agent, were not spherical in shape, in contrast to those of batch $F 1$, containing no gas-forming agent. This was due to expansion of carbon dioxide, which led to a rapid bursting of walls before they had hardened sufficiently. ${ }^{1,12-14}$ A significant difference $(P<0.05)$ was observed between the particle sizes of the uncoated and coated formulations. 
It was observed that there was an appreciably high drug release from uncoated beads in an acidic medium (Figure 1) which is not desirable. This might be because a lower concentration of SA and higher concentration of the gas-forming agent led to pore formation, which resulted in the release of the drug. The increased floating duration also led to an increase in the duration over which the drug was released in an acidic medium. Beads were dip coated with a layer of LM PC and HPMC E50 LV to reduce the release of the drug in acidic media. Formulation CF4 gives the desired lag time of 6 hours in acidic media and a rapid release (95.55\% at the end of 7 hours) in a phosphate buffer. In contrast, formulations CF1 (lag time 3 hours), CF2 (lag time 4 hours), CF3 (lag time 5 hours) and CF5 (lag time 12 hours) gave cumulative releases of $88.54 \%$ in 4 hours, $93.15 \%$ in 5 hours, $93.75 \%$ in 6 hours and $5 \%$ in 12 hours, respectively (Figure 2). It was observed that the release of drug from the coated beads in acidic media was significantly reduced compared with uncoated beads. The rigid gel structure of the PC and HPMC E50 LV coating led to a reduction in the diffusion of molecules from the inner core of the beads to an acidic medium. When the beads were transferred to a phosphate buffer of $\mathrm{pH} 7.4$ after the lag time, a pulsed release was observed because of rapid swelling and gel relaxation of pectin in the alkaline $\mathrm{pH}^{1},{ }^{13-15,21}$ As the floating duration of formulation F5 and CF5 was more than 12 hours, their lag time of release was also more than 12 hours. Formulations F5 and CF5 remained in acidic medium throughout the dissolution study leading to very slow release rate.

The percent swelling study showed that formulations CF1-CF5 showed less swelling in a pH $1.2 \mathrm{HCl}$ buffer compared with a $\mathrm{pH} 7.4$ phosphate buffer (Figure 3). In an acidic $\mathrm{pH}$, pectin remains protonated in an insoluble form, with reduced swelling. The concentration of the gas-forming agent also acts as a barrier to the absorption of water. From the floating characteristics, formulation CF1, with no gas-forming agent, was found to have the maximum swelling. The swelling decreased with increasing concentration of gas-forming agent due to the formation of void spaces in the beads the retained the maximum volume of solvent. Thus, formulation CF5 showed the minimum floating-dependent swelling because of the high concentration of the gasforming agent.

The uncoated beads of all the optimized formulations were seen to be almost spherical in shape in the scanning electron photomicrographs (Figure 4). The beads with higher concentrations of the gas-forming agent were porous, rough and spherical. The high porosity of the beads was due to the rapid evolution of carbon dioxide during beads formation as the number of pores formed is directly related to the concentration of the gas-forming agent present. ${ }^{15}$

After the formulation CF4 was exposed to extreme conditions, its physical appearance was analysed. The drug-loading efficiency, floating ability and in-vitro drug release after an interval of 1 month. No significant changes $(P>0.01)$ were observed in the physical appearance, drug loading efficiency, floating ability and invitro drug release.

\section{CONCLUSION}

PX-loaded beads of SA and HPMC K15M were prepared using the ionotropic gelation method, and their performance was analysed through in-vitro experiments. 
The release of PX from uncoated beads in acidic media due to entry of the GI fluid through the unprotected polymeric matrix was observed. So the beads were coated with a polymeric film of LM PC and HPMC E50 LV. Addition of HPMC E15 LV decreased the rupturing of the film and reduced the extent of premature drug release in the upper Gl tract. Overall, the buoyant beads exhibited gastroretention and provided a lag phase, followed by a pulsatile drug release. These would be beneficial for treating the inflammation associated with chronotherapeutic diseases. Adding HPMC E50 LV increased the flexibility, gelation, transparency and mechanical properties of the LM PC films. From the results it can be concluded that the PC: HPMC E50 LV-coated floating pulsatile beads can be used to treat the early morning inflammatory conditions in rheumatoid arthritis.

Conflict of Interest: None declared.

\section{REFERENCES}

1. Badve S, Sher P, Korde A, Pawar A. Development of hollow/porous calcium pectinate beads for floating pulsatile drug delivery. Eur J Pharm Biopharm. 2007; 65:85-93.

2. Roaa A Nief, Halah Talal Sulaiman, Saba Abdulhadi Jabir. Pulsatile drug delivery system-A review article. J Pharm Res. 2018; 12(5):764-770.

3. Yao H, Yao H, Zhu J, Yu J, Zhang L. Preparation and evaluation of a novel gastric floating alginate/poloxamer inner-porous beads using foam solution. Int $\mathrm{J}$ Pharm. 2012; 422:211-219.

4. Hamadani J, Moes AJ, Amighi K. Development and in vitro evaluation of a novel floating multiple unit dosage form obtained by melt pelletization. Int $\mathrm{J}$ Pharm. 2006; 322:96-103.

5. Sungthongjeen S, Paeratakul O, Limmatvapirat S, Puttipipatkhachorn S. Preparation and in vitro evaluation of a multiple-unit floating drug delivery system based on gas formation technique. Int J Pharm. 2006; 324:136-143.

6. Jagdale S, Suryawanshi V, Pandya S, Kuchekar B, Chabukswar A. Development of press-coated, floating-pulsatile drug delivery of lisinopril. Sci Pharm. 2014; 82(2):423-440.

7. Gadad AP, Reddy AD, Dandagi PM, Masthiholimath VS. Design and characterization of hollow/porous floating beads of captopril for pulsatile drug delivery. Asian J Pharm. 2014; 6(2): 137-143.

8. Sureshkumar R, Munikumar, Ganesh GNK, Jawahar N, Nagasamyvenkatesh D, Senthil V, Raju L, Samantha MK. Formulation and evaluation of pectinhydroxypropyl methylcellulose coated curcumin pellets for colon delivery. Asian $\mathrm{J}$ Pharm. 2009; 138-142.

9. Turkoglu M, Ugurlu T. In vitro evaluation of pectin-HPMC compression coated 5-aminosalicylic acid tablets for colonic delivery. Eur J Pharm Biopharm. 2002; 53:65-73.

10. Newton AMJ, Prabakaran L, Jayaveera KN. Pectin-HPMC E15 LV Vs pH sensitive polymer coating film for delayed drug delivery to the colon-A comparison of two dissolution models to assess colonic targeting performance in-vitro. Int $\mathrm{J}$ Appl Res Nat Prod. 2012; 5(3):1-16.

11. Hirpara F, Debnath SK, Saisivam S. Optimization and screening of different film forming polymers and plasticizers in fast dissolving sublingual film. Int J Pharm Pharm Sci. 2014; 6(6):41-42.

12. Shishu, Gupta N, Aggrawal N. Stomach specific drug delivery of \%-flurouracil using floating alginate beads. AAPS PharmSciTech. 2007; 8(2):E143-E149. 
13. Somani VG, Shahi SR, Udavant YK, Atram SC, Satpute R, Shinde NM. A floating pulsatile drug delivery system based on hollow calcium pectinate beads. Asian J Pharmacol. 2009; 120-124.

14. Gadad AP, Reddy AD, Dandagi PM, Masthiholimath VS. Design and characterization of hollow/porous floating beads of captopril for pulsatile drug delivery. Asian J Pharmacol. 2012: 6(2):137-143.

Sr.No Polymer Concentration $\begin{aligned} & \text { Crosslinking } \\ & \text { solution }\end{aligned} \quad$ Observation

15. Gadad A, Patil M, Naduvinamani S, Mastiholimath V, Dandagi P, Kulkarni A. Sodium alginate polymeric floating beads for the delivery of cefpodoxime proxetil. $\mathrm{J}$ Appl Polym Sci. 2009; 114:1921-1926.

16. Lamoudi L, Chaumeil JC, Daoud K. Swelling, erosion and drug release characteristics of sodium diclofenac from heterogenous matrix tablet. J Drug Deliv Sci Technol. 2016; 31:93-100.

17. Patel N, Lalwani D, Gollmer S, Injeti E, Sari Y, Nesamony J. Development and evaluation of calcium alginate based oral cefitriaxone sodium formulation. Prog Biomatter. 2016; (5):117-133.

18. Gadad AP, Reddy AD, Dandagi PM, Masthiholimath VS. Design and characterization of hollow/porous floating beads of captopril for pulsatile drug delivery. Asian J Pharm. 2012; 6:137-143.

19. Rathnanand $M$, Pannalal S. Formulation and in vitro evaluation of floating pulsatile tablets of nizatidine for chronotherapy of ulcers. J Pharm Res. 2011; 4(5):1388-1390.

20. Patel MA, Aboughaly MH, Schryer-Praga JV, Chadwick K. The effect of ionotropic gelation residence time on alginate cross-linking and properties. Carbohyd Polym. 2017; 155:362-371.

21. Bhattarai RS, Dhandapani NV, Shrestha A. Drug delivery using alginate and chitosan beads-An overview. Chron Young Sci. 2011; 2(4):192-196.

Bajpai SK, Tankhiwale R. Preparation, characterization and preliminary calcium release study of floating sodium alginate/dextran-based hydrogel. Part I. Polym Int. 2008; 57:57-65.

Table 1. Preliminary selection of polymer combinations and ratios for preparation of beads 


\begin{tabular}{|c|c|c|c|c|}
\hline \multirow[t]{2}{*}{1} & $\begin{array}{l}\text { Sodium } \\
\text { alginate:xanthan } \\
\text { gum }\end{array}$ & $\begin{array}{l}8: 2 \\
9: 1\end{array}$ & \multirow[t]{2}{*}{$\begin{array}{l}3 \% \text { w/v calcium } \\
\text { chloride solution in } \\
1 \% \mathrm{v} / \mathrm{v} \text { acetic acid }\end{array}$} & $\begin{array}{l}\text { Formation of highly viscous solution } \\
\text { Less viscous but not passable through }\end{array}$ \\
\hline & & $9.5: 0.5$ & & Nonspherical beads and does not floa \\
\hline 2 & $\begin{array}{l}\text { Sodium } \\
\text { alginate:HPMC } \\
\text { K100 M }\end{array}$ & $\begin{array}{l}9: 1 \\
9.5: 0.5\end{array}$ & & Not pas \\
\hline & & $\begin{array}{l}7: 1 \\
7.5: 0.5\end{array}$ & & but does not have d \\
\hline 3 & $\begin{array}{l}\text { Sodium } \\
\text { alginate:HPMC } \\
\text { K15 M }\end{array}$ & $\begin{array}{l}8: 2 \\
9: 1\end{array}$ & & $\begin{array}{l}\text { Highly viscous solution } \\
\text { Formation of rigid beads }\end{array}$ \\
\hline & & $9.3: 0.7$ & & 1 beads with des \\
\hline
\end{tabular}

Table 2. Composition, encapsulation efficiency, drug-loading efficiency, particle size and floating properties of different batches of beads

\begin{tabular}{|c|c|c|c|c|c|c|c|c|c|}
\hline $\begin{array}{l}\text { Formula } \\
\text { tion }\end{array}$ & $\begin{array}{l}\text { Comp } \\
(10 \mathrm{~m})\end{array}$ & tion of & drug polym & er dispersion & $\begin{array}{l}\text { Cross } \\
\text { soluti }\end{array}$ & $\begin{array}{l}\text { ing } \\
(50 \mathrm{ml})\end{array}$ & $\begin{array}{l}\text { Encapsulation } \\
\text { efficiency* }\end{array}$ & $\begin{array}{l}\text { Drug-loading } \\
\text { efficiency* }\end{array}$ & $\begin{array}{l}\text { Particle } \\
(\mathrm{mm})\end{array}$ \\
\hline & $\begin{array}{l}\text { Drug } \\
\text { (mg) }\end{array}$ & $\begin{array}{l}\text { SA } \\
\text { (mg) }\end{array}$ &  & $\begin{array}{l}\text { Calcium } \\
\text { carbonate } \\
\text { (mg) }\end{array}$ & $\begin{array}{l}\mathrm{CaCl}_{2} \\
(\% \\
w / v)\end{array}$ & $\begin{array}{l}\text { Acetic } \\
\text { Acid }(\% \\
v / v)\end{array}$ & & & \\
\hline F1 & 20 & 465 & 35 & 0 & 3 & 1 & $98.56 \pm 0.12$ & $28.15 \pm 0.15$ & $1.348 \pm$ \\
\hline $\mathrm{F} 2$ & 20 & 465 & 35 & 116.25 & 3 & 1 & $96.73 \pm 0.13$ & $23.70 \pm 0.22$ & $1.413 \pm$ \\
\hline F3 & 20 & 465 & 35 & 232.5 & 3 & 1 & $95.84 \pm 0.11$ & $20.48 \pm 0.18$ & $1.521 \pm$ \\
\hline
\end{tabular}




\begin{tabular}{|c|c|c|c|c|c|c|c|c|c|}
\hline F4 & 20 & 465 & 35 & 348 & 3 & 1 & $95.03 \pm 0.28$ & $18.05 \pm 0.15$ & $1.542 \pm$ \\
\hline F5 & 20 & 465 & 35 & 465 & 3 & 1 & $90.12 \pm 0.23$ & $15.30 \pm 0.13$ & $1.576 \pm$ \\
\hline
\end{tabular}

$*$ Mean \pm S.D. $(n=3)$.

$* *$ Mean \pm S.D. $(n=20)$.

++ indicates better floating property ( $45-50$ beads were floated); +- moderate floating property (2025 beads were floated);

-- poor floating property ( $0-5$ beads were floated).

Table 3. Drug-loading efficiency, particle size and floating properties of different batches of coated beads

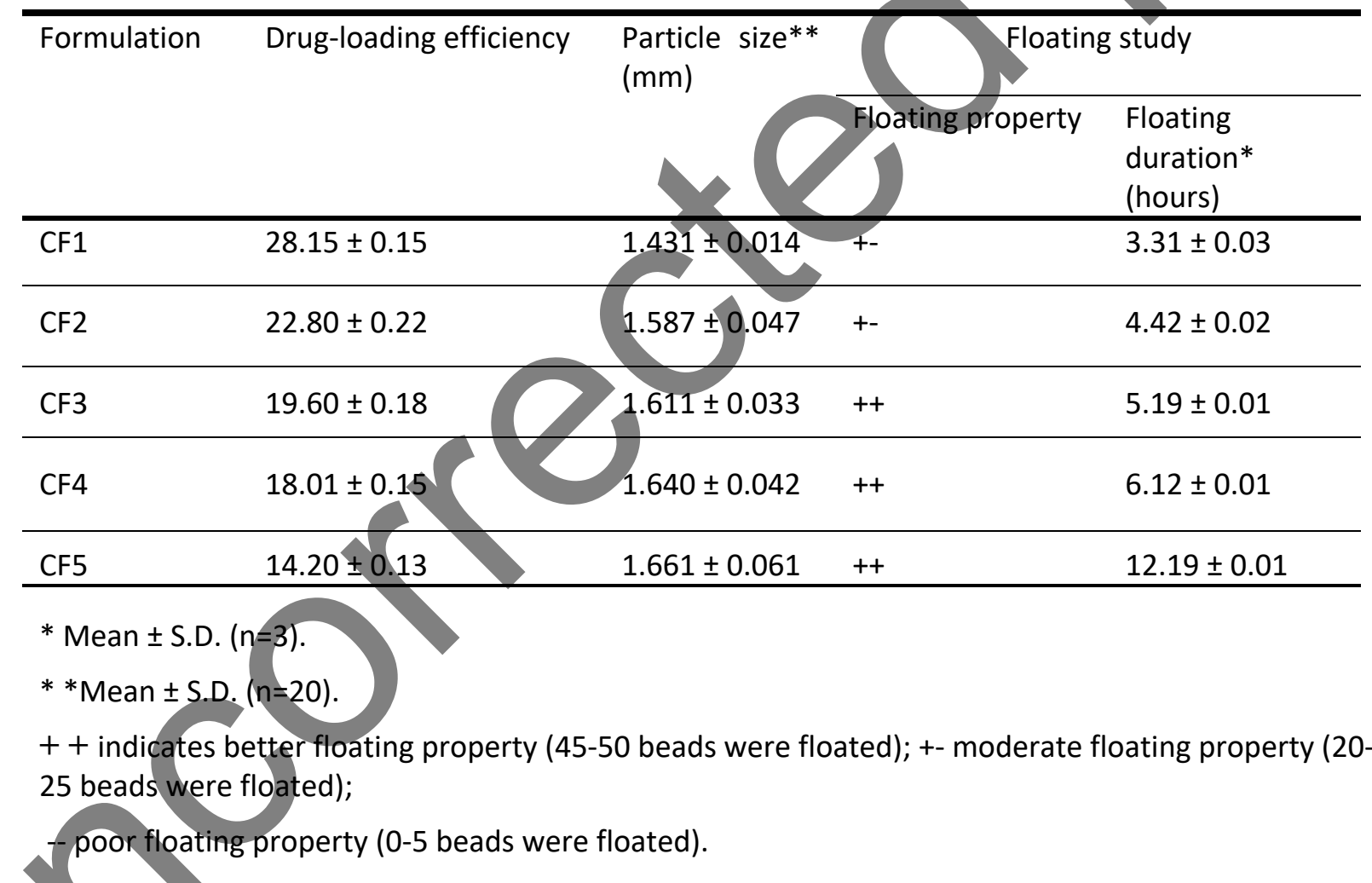


Figure 1

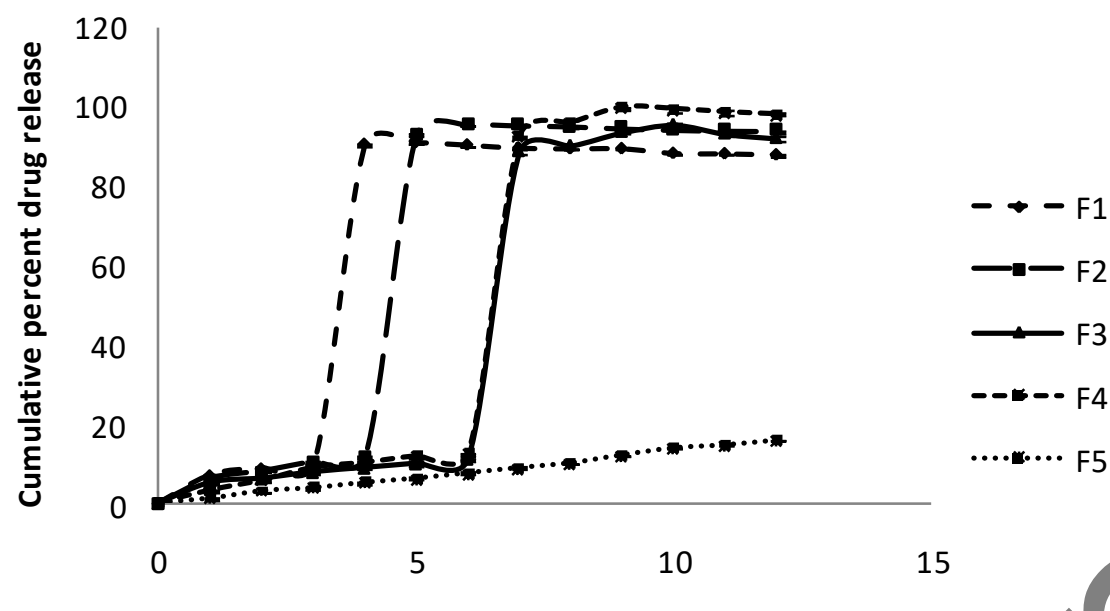

Time (h)

Figure 2

Figure3 


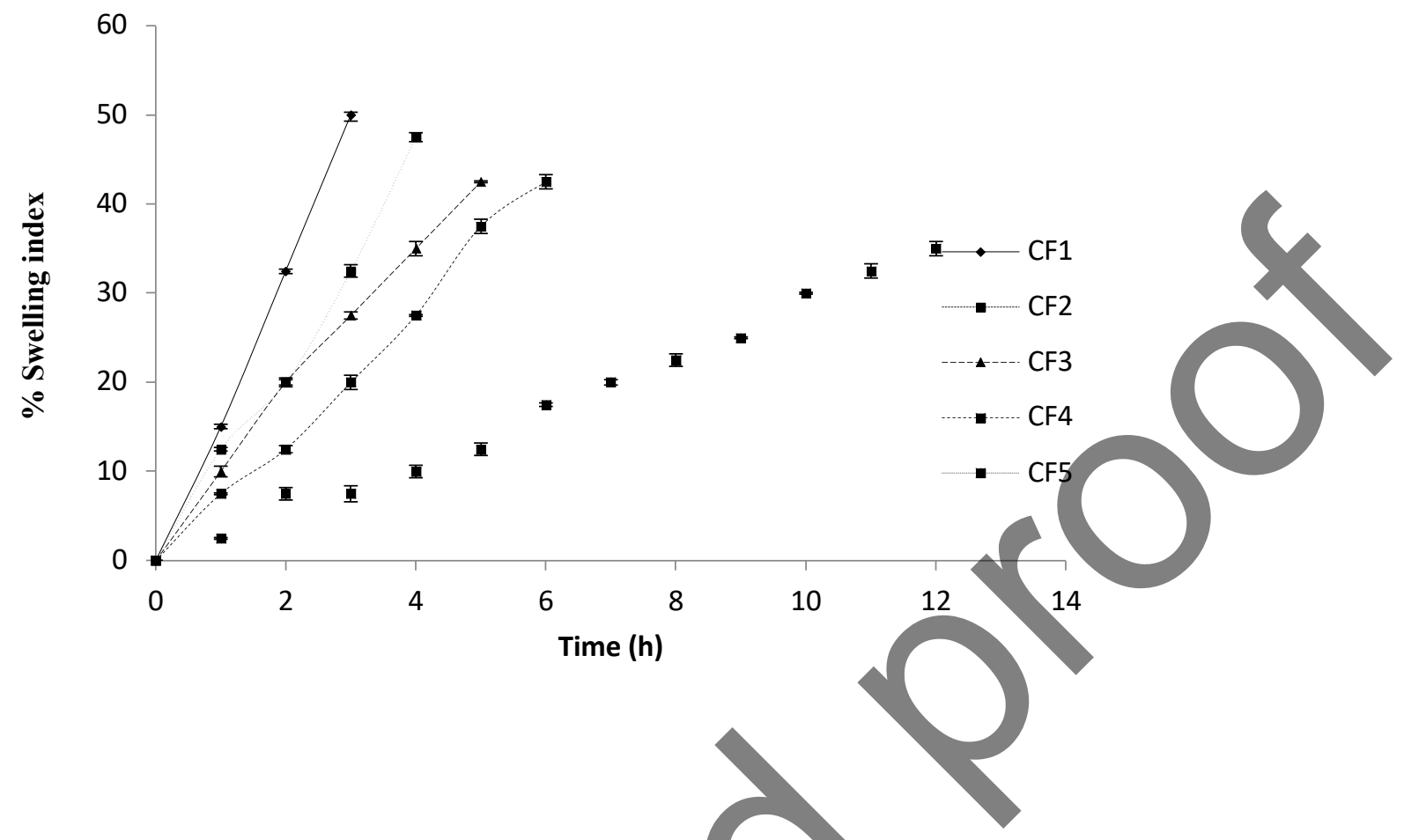

Figure 4

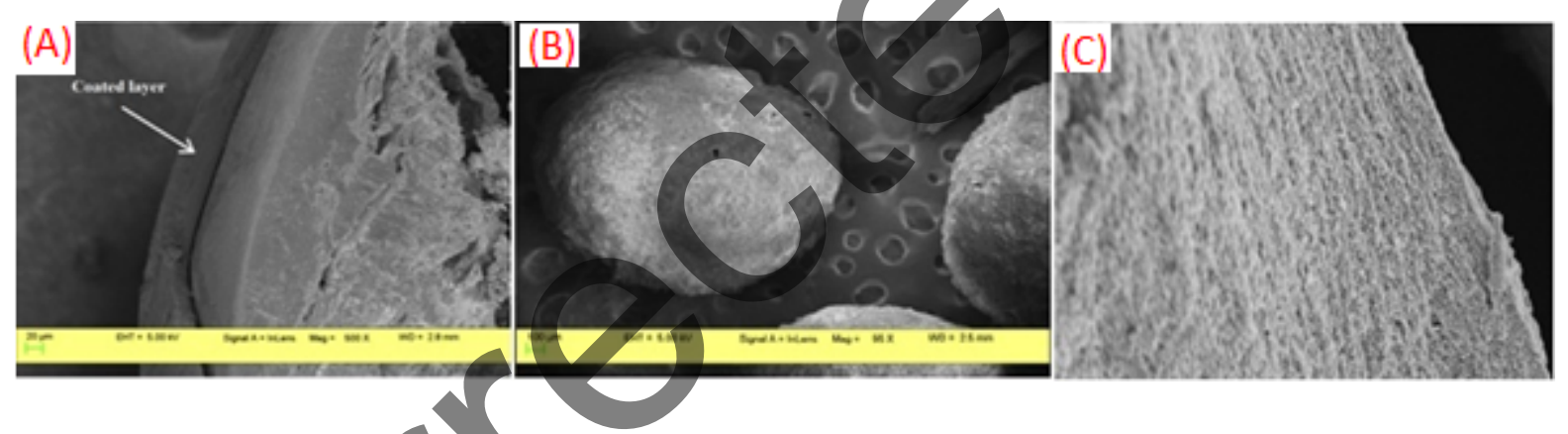

Figure 1. Cumulative amounts of PX released from beads of formulations F1, F2, F3, F4 and F5 (Mean \pm S.D., $n=3$ ).

Figure 2. Cumulative amounts of PX released from beads of formulations CF1, CF2, CF3, CF4 and CF5 (Mean \pm S.D., $n=3$ ).

Figure 3. Percent swelling index of beads of formulations CF1, CF2, CF3, CF4 and CF5 (Mean \pm S.D., $n=3$ ).

Figure 4. Morphological characterization of formulation CF4 using scanning electron microscopy (A) 
showing coating layer, (B) showing the roundness and (C) surface morphology

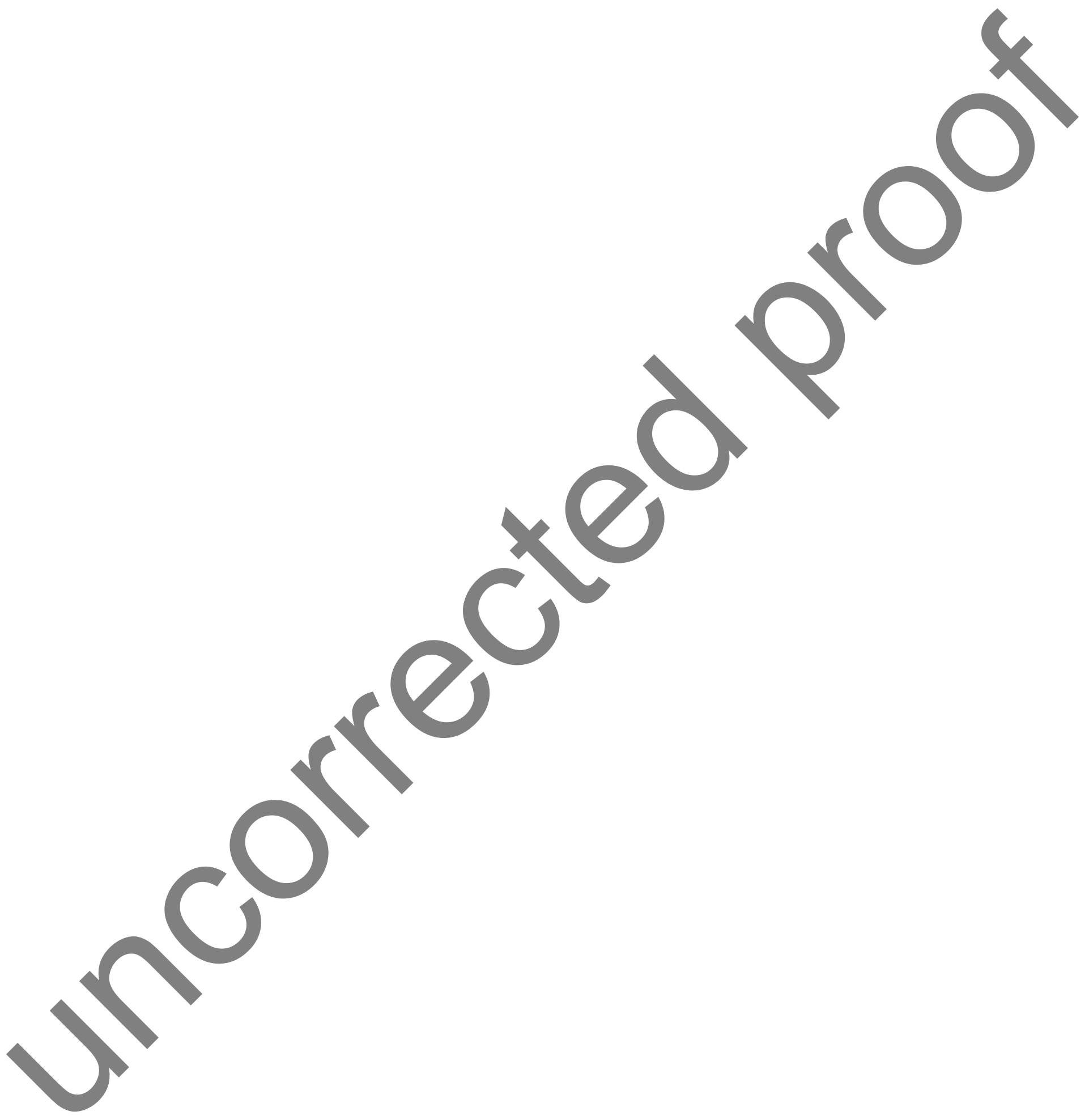

